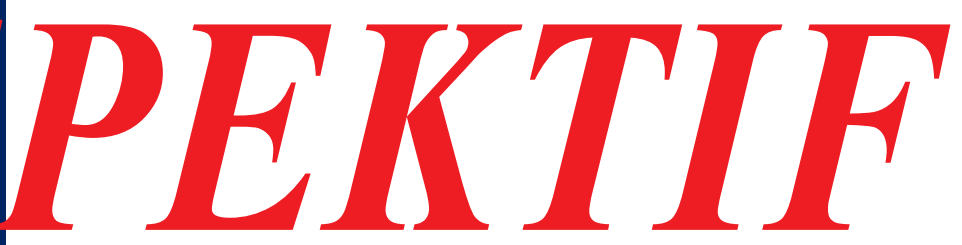

\title{
DAFTAR ISI
}

IMPLIKASI PEMBERLAKUAN UNDANG-UNDANG OTORITAS JASA KEUANGAN TERHADAP PERLINDUNGAN KONSUMEN JASA KEUANGAN DIKAITKAN UNDANG-UNDANG PERLINDUNGAN KONSUMEN

KONSEKUENSI HUKUM BAGI INDONESIA TENTANG PENGENDALIAN PENCEMARAN ASAP LINTAS BATAS PASCA RATIFIKASI ASEAN AGREEMENT ON TRANSBOUNDARY HAZE POLLUTION

KEJAHATAN PERTAMBANGAN DALAM PERSPEKTIF KEADILAN BERMARTABAT

Teguh Prasetyo

KARAKTERISTIK PEMBEBANAN JAMINAN FIDUSIA PADA BENDA PERSEDIAAN DAN PENYELESAIAN SENGKETA SAAT DEBITOR WANPRESTASI

Fani Martiawan Kumara Putra $34-47$

IMPLEMENTASI PRINSIP NEGARA HUKUM DALAM MEMBERIKAN PERLINDUNGAN HUKUM TERHADAP NOTARIS

Firman Floranta Adonara

TEORI HUKUM PANCASILA SEBAGAI SINTESA KONVERGENSI TEORI-TEORI HUKUM DI INDONESIA

PERTANGGUNGJAWABAN ORGAN YAYASAN TERHADAP KERUGIAN BIDANG PENDIDIKAN DI INDONESIA 


\title{
SUSUNAN DEWAN REDAKSI \\ JURNAL PERSPEKTIF
}

\section{Ketua Dewan Redaksi:}

Besse Sugiswati

\author{
Dewan Redaksi: \\ 1. Ari Purwadi \\ 2. Edi Krisharyanto \\ 3. Umi Enggarsasi \\ 4. Noor Tri Hastuti \\ 5. Endang Retnowati \\ 6. Joko Nur Sariono \\ 7. Ahmad Basuki \\ 8. Titik Suharti \\ 9. Suhandi \\ 10. Ria Tri Vinata \\ 11. Nur Khalimatus Sa'diyah
}

\section{Penerbit:}

Lembaga Penelitian dan Pengabdian Masyarakat (LPPM)

Universitas Wijaya Kusuma Surabaya

\section{PUBLISH OR PERISH}

Alamat Dewan Redaksi:

Jurnal PERSPEKTIF Fakultas Hukum Universitas Wijaya Kusuma Surabaya Gedung A Lantai 1 JI. Dukuh Kupang XXV/54 Surabaya 60225 Telp. (031) 5677577 Pesawat 152 Fax: (031) 5679791 e-mail: perspektif_hukum@yahoo.com Homepage: http://jurnal-perspektif.org 